\title{
Canarias en la geopolítica del franquismo durante las independencias africanas en 1960
}

\author{
Domingo GARÍ \\ Departamento de Historia \\ Facultad de Geografía e Historia \\ Universidad de La Laguna \\ domigari@hotmail.com
}

Recibido: 30-04-2013

Aceptado: 15-06-2014

\section{RESUMEN}

En 1960 la ofensiva de los países anticolonialistas en la ONU cobró un gran impulso, y de eso salió aprobada la resolución 1514 que iba a marcar el futuro del asunto. En ese contexto, por primera vez, Canarias quedó reflejada en una discusión en NN UU en los debates sobre la descolonización. El hecho alertó a los diplomáticos españoles sobre el necesario cambio de actitud que debían de tomar, si no querían que se les complicasen las cosas en relación a Ceuta, Melilla y Canarias. Para ello debían separarse de Portugal durante el tiempo que durase tal discusión en la ONU.

Palabras clave: España; Canarias; Portugal; ONU; descolonización; URSS.

\section{Franco's geopolitical approach towards the Canary Islands upon the independence of African countries in the 1960s}

\begin{abstract}
In 1960 the anti-colonial struggles at the Organization of the United Nations gained momentum, as a consequence of which, Resolution 1514 was passed, thereby setting an important precedent for the future. In a debate around decolonization processes, the question of the Canary Islands was raised for the first time within the United Nations. This fact timely warned Spanish diplomats about the need to change their approach in relation to Ceuta, Melilla and the Canary Islands - insofar as sensitive questions should be avoided-. To that end, Spain had to separate itself from Portugal until the debate on these issues came to an end.
\end{abstract}

Key words: Spain; Canary Islands; Portugal; UN; decolonization; USSR.

\section{Canárias na geopolítica do franquismo durante as independências africanas em 1960}

\section{RESUMO}

Em 1960, a ofensiva dos países anticolonialistas na ONU cobrou um grande impulso, e disso aprovou-se a resolução 1514, que iria marcar o futuro do assunto. Neste contexto, pela primeira vez, Canárias foi lembra- 
da em uma discussão nas Nações Unidas nos debates sobre a descolonização. O fato alertou os diplomatas espanhóis para a necessária mudança de atitude que deviam tomar se não quisessem complicar as relações com Ceuta, Melilla e Canárias. Para isso, deveriam se separar de Portugal durante o tempo que durasse tal discussão na ONU.

Palavras-chave: Espanha; Canárias; Portugal; ONU; descolonização; URSS.

REFERENCIA NORMALIZADA

Garí, Domingo (2013) "Canarias en la geopolítica del franquismo durante las independencias africanas en 1960”. Geopolítica(s). Revista de estudios sobre espacio y poder, vol. 4, núm. 2, 263-280.

SUMARIO: Introducción. 1. África, geopolítica y descolonización. 2. España y su diplomacia errática. 3. Canarias en la deriva diplomática española. Conclusión. Bibliografía.

\section{Introducción}

El trabajo aborda las discusiones que tuvieron lugar en NN UU al calor de los procesos descolonizadores de 1960 y de la aprobación de la resolución 1514. En tal marco las Islas Canarias estuvieron a punto de ser consideradas territorios no autónomos y en consecuencia estar sujetas a la fiscalización de la ONU, igual que los otros territorios españoles en África que para entonces tenían la misma consideración administrativa de provincias. Estos otros territorios eran Ceuta, Melilla, Ifni, Sahara, Rio Muni y Fernando Poo. Veremos cómo la torpeza diplomática española estuvo a punto de costarle caro en relación a la Islas, y cómo los países del concierto de la ONU, sabiendo de la fragilidad de la diplomacia española, agudizaron la presión sobre Canarias para doblegar la posición española en relación a los territorios coloniales que aún conservaba en África, y que facilitase de este modo el camino hacia la descolonización de los mismos.

\section{1. África, geopolítica y descolonización}

Tras la Segunda Guerra Mundial se comenzaban a hacer evidentes las reclamaciones de independencia en multitud de territorios de varios continentes. En África, en 1946, se constituyó la RDA en Bamako, pretendiendo agrupar a los partidos y movimientos del África francesa al objeto de elaborar un programa común mínimo. En 1947 en Madagascar se produjo un levantamiento nacionalista que fue seguido de una sangrienta represión por parte de las tropas francesas. En 1948 en Camerún se creó la Unión Popular de Camerún que inicia un proceso de lucha armada desde 1955 y que en 1961 fue reprimida duramente por las tropas francesas. En 1951 
Nkrumah se convirtió en jefe de gobierno de Ghana —aunque aún bajo dominación colonial-y proclamó la independencia en 1957, siendo derrocado por un golpe de Estado - auspiciado por la CIA- en 1966 debiendo huir del país para morir en el exilio en 1972. En 1958 Sekou Touré lideró la independencia de Guinea Conakry. En todo el continente los movimientos políticos se desataban, aunque con tendencias diferenciales.

El impulso de los procesos independentistas en Asia iba a estar detrás del despertar africano. La independencia de la India vehiculó su influencia hacía África a través de la Liga Árabe, y por medio de dos dirigentes de países emergentes que se convirtieron con el tiempo en referencia obligada del anticolonialismo: el hindú Nehru y el egipcio Nasser. Tras la Conferencia de Nueva Delhi en 1949 los Estados asiáticos y dos africanos reclamaron la independencia de Indonesia y además crearon un grupo de países asiáticos, árabes y africanos en la ONU (conformado por Afganistán, Birmania, India, Indonesia, Irán, Pakistán, Arabia Saudí, Egipto, Irak, Líbano, Siria, Yemen, Etiopía y Liberia) que trataron de fomentar una política independiente de los bloques, y que tenían muchos puntos de acuerdo en la cuestión colonial (Grimal, 1989; Ki-Zerbo, 2011; Iniesta, 2000; Meredith, 2011).

El refuerzo definitivo a esa tendencia se daría en la conferencia de Bandung en 1955, a la que asistieron veinticuatro países asiáticos entre los que se encontraban los cinco anfitriones (Birmania, Ceilán, India, Indonesia y Pakistán) además de los países africanos Egipto, Etiopía, Ghana, Liberia, Libia y Sudán, aunque la mayor parte del territorio africano aún seguía bajo dominación extranjera. También asistieron observadores del Magreb. La delegación más poderosa era la de China, sin duda, que iba bajo el mando de Chu En Lai. El nacimiento del Tercer Mundo como sujeto político - sometido a multitud de contradicciones- engendró y encarnó durante décadas la esperanza de construcción de un mundo en el que no tuviese lugar el colonialismo ni el imperialismo. Catalizó la esperanza de millones de personas, y en la práctica supuso un retroceso evidente de las potencias europeas y norteamericana en cuanto a su control efectivo del mundo. Las luchas antiimperialistas centrarían la potencia de cambio en las sociedades del tercer mundo hasta el final de la Guerra Fría. El nacionalismo anticolonialista y el comunismo caminaron juntos una buena parte de ese tiempo, y ambos fueron confundidos por sus enemigos, que prefirieron simplificar el discurso arguyendo al mundo que luchaban contra el comunismo, siendo esto solo una parte de la verdad (Prashad, 2012; Lacouture, 1972; Badián, 1967).

El imperialismo, además del uso intensivo que hizo de las prácticas de la guerra y la desestabilización interna, apostó por fracturar el movimiento de los países emergentes apoyando entre ellos a los representantes del tradicionalismo y del nacionalismo cultural reaccionario. Usó de manera intensiva el islamismo desde fecha tan temprana como 1962 con el patrocinio de la Liga Mundial Musulmana, y el apoyo a la reaccionaria Arabia Saudí como guardián de la ortodoxia musulmana. El islamismo fanatizado promovido desde entonces, ha sido un estilete en manos de 
las clases reaccionarias del Tercer Mundo en los países islámicos y en los EE UU. Además las potencias imperialistas promocionaron el uso del tribalismo reinventándolo a partir de ideas atávicas, y apoyando con ello los nacionalismos excluyentes de corte cultural y no antiimperialistas. Se destruyeron los pilares de las soberanías nacionales en los países emergentes:

Socavando la idea del nacionalismo, un conjunto de fuerzas sociales conservadoras y de clases poderosas unieron sus fuerzas para ofrecer una visión alternativa del patriotismo [...] El nacionalismo laico-socialista del programa tercermundista se apagó ante el ascenso de la estrella del nacionalismo cultural, un nacionalismo cultural profundamente imbuido de diferencias raciales y religiosas, entre otros atavismos parecidos (Prashad, 2012: 454).

En realidad las maniobras de las potencias colonialistas estaban en plena sintonía con la lógica de mantenimiento del poder en la escala global. Las potencias que, sin embargo, tenían sus propias contradicciones internas claramente visibles en el hecho de que existía un flanco anglosajón (GB y EE UU), que pretendía un dominio también extensivo sobre sus aliados, particularmente Francia y Alemania, preocupándose de mantener alejada a la URSS de una entente con las potencias continentales, pudieron sostener por encima de sus contradicciones estrechas alianzas para seguir dominando al Tercer Mundo:

La era de Bandung 1955-1975 y el apoyo que la Unión Soviética y China les dieron [...] [obligó] al imperialismo a actuar, no solamente aceptado la coexistencia pacífica con una área vasta que se les escapaba ampliamente ("el mundo socialista"), sino también negociando los términos de la participación de los países de Asia y África en el sistema mundial imperialista. La alineación del colectivo de la tríada bajo el liderazgo americano parecía un hecho inútil para poder dominar las relaciones Norte-Sur de la época. Esta es la razón por la cual los No Alineados se encontraron confrontados frente a un "Bloque Occidental" prácticamente sin fallas (Amin, 2004: $39)$.

El fortalecimiento de las clases reaccionarias en el interior de los países intervenidos formaba parte de esta estrategia de dominación global (Haydara, 2012).

En cualquier caso el anticolonialismo llegó a África para quedarse. En 1960, 17 países accedieron a la independencia, algunos más a lo largo de la década, y entre ellos muchos habían comenzado sus procesos de liberación en la década de los 1950. Hubo procesos que fueron conducidos por la vía del pacto, como Nigeria, y otros tuvieron que recurrir a la vía armada, como Argelia y posteriormente Angola, Mozambique o Guinea Bissau. Algunos se quedaron a medio camino entre proceso de liberación y vuelta de las potencias coloniales, como fue el caso del Congo, en donde las fuerzas imperialistas conspiraron desde el primer momento para que el proceso de independencia quedase frustrado (asesinato de Lumumba) y se instalase 
inmediatamente un gobierno corrupto y pro-occidental (Kasavubu-TshombeMobuto) (Witte, 2000; Ndaywel è Nziem, 2001). Y de forma similar en Togo, en donde el dirigente Sylvanus Olympio fue asesinado en 1963. Olympio pretendía sacar a Togo de la dependencia económica francesa impulsando una participación masiva de los togoleses en la economía, y permitiendo que otras potencias invirtieran en el país. Cuando los franceses fueron expulsados de Argelia en 1962, lo que saludó positivamente, temió que las tropas desmovilizadas fueran enviadas a su país y a otros del África subsahariana (Agbobli, 1992) ${ }^{1}$.

En los dominios franco-británicos la guerra civil no fue tan usada como en el caso de los territorios bajo dominación portuguesa, en los cuales la dictadura de Salazar usó de forma profusa la enemistad creada o imaginaria de los diferentes pueblos que vivían bajo su administración (Lacoste, 2008). Cuando los portugueses se retiraron tras la Revolución de los Claveles nuevas potencias ocuparon su lugar (EE UU y Sudáfrica), y mantuvieron las tácticas de separación de las comunidades nativas para combatir la influencia de la URSS y de Cuba, que entonces eran los apoyos del MPLA (Movimiento Popular de Liberación de Angola).

Desde el amanecer de los procesos por la independencia EE UU pretendió heredar la hegemonía en la zona y concibió todo el proceso en clave de su enfrentamiento con la URSS, lo cual le granjeó problemas, conflictos y malos entendidos durante todo ese tiempo. El conflicto en el Congo, que es el principal de los sucedidos en los 1960, tanto por la extensión del país como por el alcance histórico que ha tenido posteriormente, estuvo completamente condicionado, en cuanto a la política norteamericana en el país, por las elecciones que iban a tener lugar el 8 de noviembre de 1960. La administración norteamericana y su personal destacado en Congo, en particular su embajador Timberlake, veía con temor el cambio que podría introducir la nueva administración Kennedy en la política internacional: "No parece descabellado suponer que gran parte de la sensación de emergencia de las primeras semanas de enero (1961), que condujo a la muerte de Lumumba, no se debía a la situación interna del Congo, por muy problemática que fuera, sino al temor a un cambio inminente en Washington" (Huband, 2004: 25). Desde esta visión extremista del propio embajador y de la administración norteamericana en los asuntos para África, se estaba firmemente convencido que todo lo que no significase un control férreo de los norteamericanos en el continente africano era inmediatamente una oportunidad

\footnotetext{
${ }^{1}$ Olympio, hallándose de hecho ligado al neocolonialismo francés, tenía preferencia por la Alemania de Bonn y por Estados Unidos. Lo manifestó demasiado claramente. En diciembre de 1962, cuando las relaciones Togo-Ghana estaban aún más tensas que de costumbre, Francia propuso a Olympio una ayuda militar bajo la forma de refuerzos de paracaidistas; Olympio se negó a ello, al igual que había rehusado firmar los acuerdos de cooperación militar. Se había negado igualmente a proporcionar empleo a los paracaidistas togoleses desmovilizados por Francia y llegados a Togo. Poco después de estas negativas, cayó asesinado (Benot, 1973).
} 
para la instalación de los soviéticos en la zona. La diplomacia estadounidense veía más marxistas de los que había, y aunque no lo fuesen, como en el caso de Lumumba (Schatzberg, 1991), eran etiquetados de tales y eliminados cuando las circunstancias lo permitiesen: "En la terminología de suma cero de la Guerra Fría, el éxito estadounidense era un fracaso soviético" (Huband, 2004: 41). La confrontación Este-Oeste tuvo un rol decisivo en el proceso descolonizador y su largo brazo también afectó a España.

\section{España y su diplomacia errática}

En 1955 España fue admitida como miembro pleno de NN UU y por ello tuvo que aceptar los documentos y principios que se habían establecido en relación a multitud de asuntos, incluidos los que tienen que ver con la descolonización (Lleonart y Amsélem, 2002; Pereira Castañares, 2001; Tusell y Avilés Farré, 2000; Espadas Burgos, 1988). El primero y más importante es la Carta de la Naciones Unidas. Un documento de principios que se convierte en herramienta de cumplimiento más o menos obligado, en función de la fortaleza de cada país, pero que en cualquier caso, marca recomendaciones muy difíciles de no atender si no eres miembro permanente del Consejo de Seguridad.

Los títulos XI, XII y XIII de la Carta se ocupan de los territorios no autónomos y de las relaciones de estos con las metrópolis y las potencias fiduciarias. Los artículos específicos son los comprendidos entre el 73 y el 91, y para el tema que tratamos nosotros el principal es el primero de todos ellos, es decir, el artículo 73, en el que se dice lo siguiente:

Los Miembros de las Naciones Unidas que tengan o asuman la responsabilidad de administrar territorios cuyos pueblos no hayan alcanzado todavía la plenitud del gobierno propio [...] [se obligan a]: "e) transmitir regularmente al Secretario General, a título informativo y dentro de los límites que la seguridad y consideraciones de orden constitucional requieran, la información estadística y de cualquier otra naturaleza técnica que verse sobre las condiciones económicas, sociales y educativas de los territorios por los cuales son respectivamente responsables".

La petición de información que hacía NN UU a España sobre sus territorios no autónomos (TNA, en adelante) iba a colocar a la diplomacia del general Franco en un buen aprieto.

En febrero de 1956, según narra el diplomático Jaime de Piniés y Rubio, entonces miembro de la misión permanente en Naciones Unidas junto con el embajador Lequerica, el Secretario General de la ONU envió una nota a la delegación española recordándole la obligación que tenía España de dar información sobre los TNA que mantenía bajo su administración. La nota se recibió el 28 de febrero de 1956. Esta 
práctica era común desde la fundación de la ONU y como España terminaba de integrarse en la organización (14 de diciembre de 1955) era conminada a ello junto con los otros miembros que ingresaron a la vez que España. Entre los nuevos miembros se encontraba también Portugal, e iba a ser igualmente exigida en cuanto a sus responsabilidades hacia sus territorios coloniales. Incluso más, dado que Portugal poseía un respetable imperio colonial en África, a diferencia de España, que tenía unos territorios mucho menores y de infinito menor peso demográfico (De la Torre Gómez y Vicente, 1998).

Desde el principio, tanto Portugal como España, se resistieron a dar la información solicitada por el Secretario General, aduciendo que los territorios de los que se pedía información eran provincias y que ninguno de los dos países se sentía concernido por el artículo 73 de la Carta. Así que el asunto comenzó pronto. Nada más ser admitido como miembro de pleno derecho de NN UU España intentaba torear los acuerdos y principios de la ONU que consideraba lesivos para sus intereses en ultramar, y demoró la contestación durante un año. Los portugueses, por su lado, preparaban una guerra colonial en Angola y otras en Guinea y Cabo Verde "arrestando, torturando, masacrando", mientras "intentan vanamente convencer al mundo de que no tienen colonias y de que nuestros países africanos son «provincias de Portugal»" (Cabral, 1975).

En 1958 se hizo cargo de la delegación española en la ONU el embajador Manuel Aznar Zubigaray. Pero el cambio de embajador no significó un cambio de orientación de la política española. Al decir del diplomático Piniés había dos posiciones diferenciadas. Una era la mantenida por el Ministro de Asuntos Exteriores, Castiella, favorable a transmitir la información solicitada por la ONU, y otra que la suscribía Presidencia del Gobierno, más en concreto, la Dirección General de Marruecos y Colonias dependiente de aquél, que era contrario a dar tal información. Para que la fantasía se ajustase a la realidad en 1959 una ley realizada ex profeso dictaminó que los territorios africanos de Rio Muni y Fernando Poo, Ifni, Sahara, Ceuta y Melilla, eran provincias españolas con la misma consideración que los territorios situados en la propia península ibérica (Espadas Burgos, 1988; Calduch Cervera, 1994).

La delegación diplomática española redactó una carta para enviar al Secretario General de la ONU tratando de aunar, según cuenta Piniés, las dos posiciones encontradas en el seno del gobierno español; aunque a todas luces bien pudiera parecer una maniobra de dilación y de postergación de las responsabilidades. En ella se dice:

El Gobierno español, deseoso de esclarecer como siempre las preguntas formuladas por el Secretario General en su memorándum de 24 de febrero de 1956, se permite someter las siguientes observaciones: España no posee Territorios No-Autónomos, pues los que están sometidos a su soberanía en África tienen la consideración y clasificación de provincias españolas, con arreglo a la legislación vigente. En consecuen- 
cia, el Gobierno español no se siente incluido en el artículo 73 de la Carta de las Naciones Unidas referentes a Territorios No-Autónomos sin existencia legal dentro de la organización administrativa española. Sobre la situación de las provincias españolas en África se han publicado y se publican constantemente documentos oficiales y de todas clases, y aun cuando ningún motivo legal nos obliga a ello, deseosos de responder al espíritu de las Naciones Unidas, tengo mucho gusto en poner a su disposición estas publicaciones para que sirvan de esclarecimiento al Secretario General ${ }^{2}$.

Marruecos, que ya era un país independiente y que aspiraba a ampliar su territorio sobre algunas de las posesiones española mostró prontamente su disconformidad con la actitud española de no informar sobre sus TNA, y manifestó sus reservas sobre el Sahara, Ifni, Ceuta y Melilla. Sobre el terreno apoyaba a los grupos irregulares del Ejército de Liberación Nacional que entraron en combate desde el 23 de noviembre de 1957 contra las fuerzas españolas acantonadas en Ifni, dando así origen a una guerra que pretendía expulsar a los españoles del territorio. Visto el curso de los enfrentamientos España tuvo que replegar sus tropas hasta la ciudad de Sidi Ifni, y allí permanecieron hasta que una década más tarde se produjo la retirada total de España (Canales y Del Rey, 2010; Diego Aguirre, 1993).

Pasó el año 1958 sin que España se aviniese a dar la información solicitada por la ONU, y pudo mantener la dilación en los términos del documento citado y haciendo un uso sistemático del reglamento de discusión de NN UU al objeto de retardar y entorpecer las peticiones de información. Pero el ascenso de los países emergentes ponía las cosas más complicadas incluso a una potencia menor como era el caso de España, cuyasd posesiones coloniales se reducían, al decir de un diplomático portugués, a "cuatro palmeras y unos montones de polvo"3. Desde noviembre de 1959 Marruecos abrió diáfanamente el objetivo de atacar a España en el seno de la Asamblea General. El delegado marroquí Sidi Baba señaló que su gobierno consideraba a Ifni y a Sequia el Hamra como territorios integrantes del reino de Marruecos y convidaba a España a avenirse a un acuerdo amistoso sobre el asunto "como sucedió recientemente cuando España renunció a sus reivindicaciones sobre Tarfaya"4. Marruecos obtuvo el apoyo inmediato de Yemen, Libia y Líbano en lo relativo a la reivindicación de Mauritania e Ifni ${ }^{5}$.

\footnotetext{
2 ONU. Documento A/C.4/385.

${ }^{3}$ MAE, expediente 029770, anejo 1181/17. El debate sobre el colonialismo. 9 diciembre 1960.

${ }^{4}$ MAE, expediente 6168/80. El problema de la información sobre territorios no autónomos en la Cuarta Comisión de las Naciones Unidas. 16 de febrero de 1960. Véase Iglesias (2010).

5 La Monarquía alauita hizo suya la reivindicación del "Gran Marruecos" (definido años antes por el Istiqlal), que abarcaba zonas donde las autoridades marroquíes habían tenido en algún momento histórico influencia político-religiosa, aunque no necesariamente hubieran ejercido su soberanía política: Ceuta, Melilla, los peñones de Vélez de la Gomera, Alhucemas y las islas Chafarinas, Ifni, el Sáhara español y parte del argelino, Mauritania, el noroeste de Malí y San Luís de Senegal. Véase López García y Hernando de Larramendi, 2010.
} 
El nacimiento de nuevos países africanos y asiáticos hacía más difícil la posición de los países colonialistas en general, y de Portugal y España en particular, por su actitud de negación a reconocer el hecho evidente de que poseían colonias bajo su administración. Así que esta presión fue dando frutos, siendo uno de ellos la decisión tomada en el transcurso de la XIV Asamblea General en los meses finales de 1959 de crear un comité específico (Comité de los Seis) para que se encargara de estudiar y señalar claramente cuáles son los términos que definen a un TNA y cómo debe llevarse a cabo la transmisión de información una vez que es solicitada por la ONU. Son las resoluciones 1467 y 1468 de 12 y 15 de diciembre respectivamente de 1959.

Sobre esta nueva legalidad se le solicitó otra vez información a España acerca de los TNA, y la respuesta redundó en la ofrecida con anterioridad. Los países afroasiáticos se mostraron molestos con la misma, así como la URSS y sus aliados de la Europa oriental, e incluso países como Venezuela o México tanto como Marruecos, por consideraciones de otro orden, se mostraron en desacuerdo con la negativa española. Este último país tenía muy buenas razones materiales para incidir contra la posición española. Desde la guerra de Ifni abiertamente solicitaba que España informara sobre el propio Ifni, el Sahara, Ceuta y Melilla (Iglesias, 2010; Del Pino, 1983).

En la sesión 970a la India lamentó el hecho de que España se negara a regularizar su aportación de información aduciendo que "las Cortes españolas estaban estudiando un proyecto de ley sobre el estatuto de las provincias españolas de ultramar", respecto a lo que apostilló el delegado hindú: “el gobierno de España, al parecer decidió no transmitir información sobre sus territorios de ultramar e informó al Secretario General que no estaban dispuestos a hacerlo" ". India conminaba a España a reconsidera su postura. La delegación española, por su parte intervino para manifestar que el hecho de que el gobierno de su país examine diversos planes en relación a sus provincias de África no debe llevar a sorpresa, y que, en cualquier caso, los asuntos de la política interna de España no son pertinentes en este debate. La posición oficial fue fijada tajantemente por el embajador Aznar. España no posee territorios autónomos, "no siendo aplicables por tanto las disposiciones del Capítulo XI de la Carta", lo que no obsta para que como signo de buena voluntad pueda facilitar información a Naciones Unidas "sobre aquellas provincias de España que pueden ser de interés para Naciones Unidas con fines meramente informativos conforme al inciso e del artículo 73", lo cual hará, sentenciaba el diplomático español, "en el momento oportuno, sin que tal hecho afecte a la posición de principio de su Gobierno" ". La intervención de Aznar fue recibida con esperanza en la

\footnotetext{
${ }^{6} \mathrm{MAE}$, expediente $6168 / 80$.

${ }^{7}$ Ibid.
} 
Asamblea, al entender ésta que significaba que España se avenía a las disposiciones de la ONU al respecto. El juego no terminaba ahí. Si la declaración de Aznar dejaba tranquilos a los miembros de la Asamblea, sin embargo, desdecía la posición oficial del gobierno español al aceptar los términos del inciso e del artículo 73. Para solventar el asunto el representante permanente de España en NN UU se reunió con el Jefe del Servicio de Sesiones encargado de sentar las actas de las sesiones y le indicó que algunos términos de la intervención del embajador de España debían ser modificados en el acta. De ella debería desaparecer la frase en que se aceptaba el inciso e del artículo 73 y tendría que ser sustituida por la frase "para el esclarecimiento del Secretario General". España mantenía así el doble lenguaje.

Un torrente de países pusieron el punto de mira sobre España reclamándole el aporte de información sobre los TNA. Marruecos, Liberia, Indonesia y los satélites de la URSS así lo hicieron. La creación del Comité de los Seis iba a servir para aumentar la presión al respecto, e iba a debilitar la posición ambigua y de intransigencia de Portugal y de España. La negativa española fue lo que motivó que Canarias se viera envuelta en el entuerto de los TNA, temiéndose que de haber sido finalmente incorporada de manera abierta en las discusiones de la ONU, los problemas para España en las Islas podían comenzar a crecer.

\section{Canarias en la deriva diplomática española}

La reclamación marroquí sobre Ceuta y Melilla sumado a la negativa portuguesa a dar información sobre sus territorios, y la parecida actitud española, que daba información pero sin reconocer la existencia de los TNA, exasperó a muchas delegaciones que entonces pasaron a la ofensiva. Se preparó un proyecto de resolución impulsado por Afganistán, Birmania, Ceilán, Ghana, Guinea, India, Nepal y Nigeria en el que además de incorporar a los territorios ya reclamados se pretendió incluir a las Islas Canarias (Piniés y Rubio, 2001).

Cuando se habló de ello, la delegación española hizo esfuerzos considerables porque no trascendiese a la prensa internacional la mención sobre las Islas. Tras esa primera amenaza no consumada de incorporar a Canarias dentro de los TNA, el Comité de los Seis se decantó finalmente por señalar que tales territorios en el caso español eran Ifni, El Sahara, Fernando Poo y Rio Muni. Delegados de varios países se sintieron incómodos con esa breve lista de territorios señalados, y dado que el caso de Portugal y España se estaba tratando paralelamente, quizá motivado por alguna confusión no premeditada, el delegado de la República Árabe Unida - formada entonces por Egipto y Siria - dijo que si se nombraban estos territorios y no los otros que faltaban se les estaría negando el futuro derecho a su independencia. Entre estos territorios que faltaban el representante permanente de la República Árabe Unida, Loutfi, mencionó a Mozambique, Angola y las Islas Canarias. La contestación española fue de inmediata defensa de las Islas. El embajador 
Manuel Aznar mostró su "protesta más enérgica, su repulsa más implacable por esta agresión inconcebible, una ofensa sin precedente, una monstruosidad jamás esperada del Delegado de un país amigo, la RAU, contra España, contra su pueblo entero y contra un trozo sagrado de nuestra Patria, las Islas Canarias" (Piniés y Rubio, 2001: 32). El ministro Castiella felicitó por telegrama cifrado al representante Aznar por el "acierto con que ha sabido minimizar alcance tan enojoso incidente buscándole solución apropiaba" ${ }^{8}$. La labor diplomática continuó en reuniones paralelas al desarrollo de la Asamblea General. Aznar contactó con el representante permanente de la RAU en NN UU, Loutfi, y con el embajador Rifai y acordaron retirar la mención a Canarias y la réplica de España de las actas oficiales. Así se contuvo primeramente este enojoso problema para la diplomacia española, aunque el asunto iba a estar asomando a lo largo de todo el mes de noviembre. La aparición de Canarias llevó a que la diplomacia española reflexionara sobre este hecho con más atención.

Esta fue la primera vez que Canarias quedó reflejada en una discusión en NN UU. El hecho alertó a los diplomáticos españoles sobre el necesario cambio de actitud que debían de tomar si no querían que se les complicasen más las cosas, y pusiesen en peligro los territorios que querían salvaguardar sobre todos los demás: Ceuta, Melilla y Canarias. Así que tras negociar con los representantes de la India, Manuel Aznar consiguió suprimir la cita de los territorios españoles, al darle garantías a los hindúes de que España observaría las obligaciones de la Carta de la ONU e informaría al Secretario General sobre los TNA. La estrategia española consistía "en pasar desapercibidos o poco percibidos" además de mantener la posición de principio consistente en que "nosotros no damos información sobre territorios no autónomos que no tenemos, pero, en cambio, con espíritu liberal y deseoso de que diáfanamente conozca el mundo cuanto realizamos en cumplimiento de deberes históricos en África, hacemos llegar al Secretario General cuanta documentación

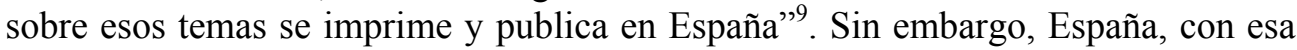
estrategia siguió exacerbando los ánimos de los miembros de la IV Comisión y del conjunto de los delegados de los países que estaban dispuestos a avanzar hacia la descolonización total.

Los soviéticos estaban decididos a llevar el tema de la descolonización hasta sus últimas consecuencias y desde septiembre el propio Kruchev envió una carta fechada el día 23 y dirigida al Presidente de la Asamblea General de la ONU (A/4501, 23 de septiembre de 1960), aunque la carta no se leyó hasta el día 28 de noviembre de 1960, y no por Kruchev sino por Zorin, representante permanente de la delegación soviética en la ONU. En dicho documento la URSS conminaba a que se concediese

\footnotetext{
${ }^{8}$ Real Academia de la Historia (RAH). Fondo Castiella, documento 1140.C75.

${ }^{9}$ MAE. Expediente 029770. Docu. Mensaje estrictamente confidencial de 21 de octubre de 1960.
} 
inmediatamente "a todos los países coloniales, a los territorios en fideicomiso y a los demás territorios no autónomos la plena independencia [...] [y] eliminar todos los puntos de apoyo con que cuentan el colonialismo en forma de posesiones y zonas arrendadas en territorios extranjeros". Las razones de esa exigencia iban explicadas en el documento $\mathrm{A} / 4502$. El alegato soviético no dejaba lugar a dudas en cuanto a sus intenciones y es el documento de naturaleza más anticolonialista leído en aquel tiempo en la tribuna de $\mathrm{NN} \mathrm{UU}^{10}$.

Durante el debate general en la asamblea que arrancó el 3 de noviembre, se reconoció una actitud distinta de España que la que mantenía Portugal, pero se dijo que en la práctica España tampoco estaba suministrando la información requerida sobre sus TNA, y se recordó que desde 1959 se había negado a reconocer que poseía territorios bajo administración colonial. La delegación de Liberia tomó la palabra para recordarle a la Asamblea General que tiene la "obligación de exigir a España que cumpla las obligaciones que le impone la Carta en relación a los territorios que administra" $" 11$.

Los soviéticos, al borde del mediodía, hicieron su intervención a través del delegado Kuchava, quien adujo que no creía que el tema de la descolonización pudiese tratarse desde un óptica de tratado académico, porque las potencias coloniales se han dedicado a elaborar estrategias de dilación arguyendo cuestiones terminológicas, para evitar dar respuesta a las demandas de independencia de los pueblos bajo su dominación:

Es inútil hacer investigaciones jurídicas, puesto que Angola, Mozambique, la llamada Guinea portuguesa, Cabo Verde y las Islas de Santo Tomé y Príncipe son colonias de Portugal, y que Ifni, el llamado Sahara español y las Islas Canarias son colonias de España, adquiridas en todos los casos por conquistas militares que condujeron a la esclavitud de los pueblos de los territorios ${ }^{12}$.

Para España, haber sido analizada de forma conjunta con Portugal le trajo problemas evidentes, sobre todo en relación a Canarias, Ceuta y Melilla. De ahí que la delegación española en la ONU y el Ministerio de Asuntos Exteriores quisiesen separar la posición española de la portuguesa, en contra de la opinión de Presidencia del Gobierno que seguía siendo partidario de mantener la unidad de acción con Portugal en el tema de los TNA, y eso de manera incomprensible, y a pesar de que la relación de Portugal con sus colonias podía dejar al descubierto la fragilidad de la

\footnotetext{
${ }^{10}$ En una biografía sobre Kruschev se dice que el dirigente soviético asistía a la Asamblea de la ONU en octubre de 1960 para tratar los dos temas suyos "favoritos...el desarme y la descolonización" (Taubman, 2005: 567). Véase Heffer y Launay (1992), Hobsbawm (1995) y Martínez Carreras (1986).

${ }^{11}$ Asamblea General de la ONU. Decimoquinto periodo de sesiones. IV Comisión 1034a, 3-11-1960.

${ }^{12}$ Ibid.
} 
posición española (De la Torre Gómez y Vicente, 1998; De la Torre y Sánchez Cervelló, 1992; Calduch Cervera, 1994).

Tras la sesión del día 3 la diplomacia española trató de llevar a cabo una política que poco a poco la distanciase de Portugal, porque mantener la estrategia de seguir vinculado a este país podría acarrear más problemas que beneficios. El embajador Manuel Aznar que en ese momento encabezaba la delegación española en NN UU le escribió al Ministro en esa clave: "No hay que minimizar, ni dramatizar nuestra situación", dijo el embajador, en carta del 7 de noviembre dirigida al "querido Ministro y amigo". La situación es la siguiente: "Hostilidad arrasadora contra todo lo que directa o indirectamente huela a colonialismo en África; cólera desatada contra Portugal", y a continuación viene lo que sintetiza la posición de Aznar contra la opinión oficial del gobierno en Madrid:

[Portugal] se ha encastillado en una política poco práctica; y ataques muy moderados a España, nacidos de nuestro apoyo leal a los portugueses. El llamado bloque anticolonialista puede ganar hoy las votaciones que quiera. Ni nuestros amigos más queridos se atreven a ir más allá de una vergonzante abstención. De momento, las voracidades coloniales aparecen representadas por Portugal, África del Sur y España. Es fabulosamente cómico esto de vernos incluidos en el club de los poseedores de colonias $^{13}$.

De aquí en adelante el equilibrio diplomático español tendría que centrarse en mantener su tradicional amistad con Portugal, pero paralelamente irse alejando de su postura de intransigencia en la IV Comisión. El desvelamiento de las tiranteces entre Portugal y España comenzó a hacerse patente en la documentación diplomática. Aznar lo dejó reflejado:

Del embajador [portugués], señor Vasco Garín, no te puedo decir nada muy alentador para nosotros [...] Es un hombre de una terrible indiferencia ante todo lo español. Me sacó el otro día de quicio el ridículo gozo que mostraba ante el episodio de las Islas Canarias, suscitado, a mi juicio, por la superficialidad y la ignorancia del egipcio Rifai ${ }^{14}$.

Las cosas no pintaban bien para España y la delegación hispana en la ONU entendió que la sospecha de que en la lista de TNA se incluyera a Ceuta y Melilla y que la mención de Canarias "aunque no había sido recogido por la prensa, flotaba en el aire (y) no se podía perder ni un solo minuto". La propuesta que le hizo de manera no oficial el embajador de Marruecos a Lequerica el día 11 de noviembre

\footnotetext{
${ }^{13}$ MAE. Exp 029770. Docu. 1146/3. Misión permanente de España en las Naciones Unidas.

${ }^{14}$ Ibid.
} 
referida a Ceuta y Melilla consistía en resolver de mutuo acuerdo "el problema de ciudades enclavadas en territorios ajenos", lo que hacía referencia también a Gibraltar. Luego le advirtió al diplomático español que: "Una irresistible corriente de opinión en mi país lleva a los marroquíes a reclamar Ceuta y Melilla, y deseamos hacerlo en términos amistosos y encauzándolo como problema general para que al mismo tiempo tenga satisfacción España"15.

España seguía queriendo demorar la obligación de transmisión de información, y por eso se aventuraba en explicaciones que ya nada tenían que ver con lo que esperaba el resto de países. Ninguno quería divagar sobre principios genéricos sobre soberanía nacional, nación, reforma constitucional u otros de esa índole si lo que estaba tratándose era solo la exigencia de que las potencias coloniales tenían la obligación de dar información sobre sus territorios administrados y avanzar hacia el proceso de independencia de los mismos. Manuel Aznar dijo que lo expuesto por la Comisión no dejaba de ser solo una cuestión de principios, muy nobles, aduce, pero "muy difícil de alcanzar". En cualquier caso, el embajador español reafirmó la negativa de su país a transmitir dicha información y se encomendó a las razones morales para no hacerlo:

La Comisión no ha seguido las reglas de una verdadera discusión sobre principios universales, aplicables a todos los Estados Miembros. Al considerar a España como a un monstruo que se alimenta con la carne y la sangre de los pueblos africanos y a los adversarios de España como a un grupo de arcángeles que defendieron la libertad del mundo, por una discriminación incalificable se ha llegado a acusar y a condenar a un país en virtud de una ley que aún no existe. Cuando la escala de los valores se invierte de esta manera, no cabe sino esperar que las nuevas fuerzas morales y espirituales restablezcan la justicia escarnecida y reparen el $\mathrm{mal}^{16}$.

Manuel Aznar no hacía sino repetir el abc de los principios del franquismo y reavivaba la idea de su lucha contra el mal encarnado en los enemigos de España.

En la siguiente sesión celebrada el día 11 de noviembre, España, estando en el punto de mira de las intervenciones del resto de países, negoció con la India la supresión a la mención de los territorios y en contrapartida le aseguró que transmitirían información al Secretario General. Pero España se guardaba bajo manga el hecho de que transmitiría la información sin reconocer que se trataba de TNA, sino de provincias tal cual venía haciendo en los meses precedentes. El delegado soviético de origen ucraniano, Neklessa, se opuso a la enmienda introducida por India y mostró su disconformidad con el hecho de que desapareciera la lista de territorios a nombrar. Y entonces señaló nuevamente que España debía dar información sobre

\footnotetext{
${ }^{15}$ MAE. Exp. 029770. Docu.1152/7.

${ }^{16}$ Manuel Aznar, decimoquinto periodo de sesiones, IV Comisión, 7/11/1960.
} 
sus TNA tal y como se pedía en la resolución 1541. El delegado soviético puntualizó que los territorios de los que se trataba eran Ifni, Sahara Occidental, Fernando Poo, Río Muni y las Islas Canarias. Marruecos añadió a la lista las ciudades de Ceuta y Melilla. La presión sobre la diplomacia española parecía que iba a comenzar a dar sus frutos porque el Embajador Lequerica transmitió a la Presidencia del Gobierno en Madrid:

[S]eguir utilizando los términos de provincias en los territorios de África era sumamente perjudicial. El identificar las Islas Canarias con nuestras posesiones de Guinea nos iba a crear serias dificultades y a tal efecto marcaba la línea que debía de seguirse en el futuro, añadiendo que convendría dar un paso más y deberíamos señalar que estábamos dispuestos a dar información en la forma en que venían haciéndolo otros países (Piniés y Rubio, 2001: 34).

España quedó obligada, aun en contra de su parecer, a reconocer que tenía TNA y que debía transmitir información sobre ellos. En el debate que acompañó a la aprobación de la resolución 1514 la estrategia adoptada por la delegación española, entonces encabezada por Lequerica, consistió en "procurar pasar desapercibidos y votar luego sin demasiadas cavilaciones los proyectos a los cuales se adhieran las potencias occidentales de mayor autoridad e incluso salvar en algunos casos nuestra originalidad propia; pero siempre con tendencia a la evasión" ${ }^{17}$. Las posesiones españolas en África no merecían una batalla a brazo partido: "Agotada casi nuestra historia colonial en una magnífica creación americana" ", las pobres y poco importantes posesiones en el continente africano no reclaman la atención de la diplomacia franquista, dolida en su memoria porque durante los siglos XIX y XX fueron "víctimas de la más decidida exclusiva europea contra nosotros, con lo que casi nos eliminó de África" "19. Alejados del punto de mira por la insignificancia de sus posesiones la diplomacia española hace lo posible por no ser colocada en "la lista de los imperialistas", aunque bien le hubiera gustado serlo si ello significaba que junto a los discursos en inglés y francés "de tanto delegado negro" se hubiese oído el español "de otros africanos de lengua, religión y cultura españolas llegados también a esta aula internacional tan considerable" 20 .

El 7 de diciembre volvían a encenderse las alarmas de la delegación española, cuando el delegado soviético, Zorin, citó en las actas, no en el discurso, a las Islas Canarias. Narra el embajador español que todo discurría por un camino plácido y que España seguía ignorada en los debates, incluso por la delegación soviética,

\footnotetext{
${ }^{17}$ MAE. Exp.029770. No $80,25 / 11 / 1960$.

${ }^{18}$ Ibid.

${ }^{19} \mathrm{Ibid}$.

${ }^{20}$ Ibid.
} 
hasta que "surgió el desatino de Zorin, al colocar en la edición inglesa y francesa de su discurso las Islas Canarias entre los países sometidos a régimen colonial. Sin esta alusión, todo aconsejaría como hasta ahora, seguir nuestra política de silencio y aprovechamiento del elogio de los demás. Y aun así, voy a limitar al caso concreto de la monstruosa falsedad histórica y atentado a la unidad de España, de Zorin, la rectificación en la primera sesión que se celebre" ${ }^{21}$. Se arreglaría sin armar el más mínimo revuelo para desactivar el intento de involucrar a España en las tormentosas sesiones sobre la descolonización. Ahí concluyó la cuestión canaria en el seno de NN UU en 1960.

\section{Conclusión}

Los procesos de descolonización cobraron, tras la aprobación de la resolución 1514 de NN UU, un impulso enorme, abriendo la puerta a las independencias de los países que permanecían bajo dominación colonial. El nacimiento del Tercer Mundo en Bandung en 1955, y las independencias africanas y asiáticas, cambiaron el mundo de postguerra y obligaron a los imperialismos a retroceder y fabricar nuevas formas de dominación poscoloniales.

España, en tanto potencia de segundo orden, se vio arrastrada por los acontecimientos del momento y por la elección de una estrategia diplomática errónea. Su apuesta por copiar el modelo portugués de defensa de las colonias, declarándolas provincias, situó a Canarias en una difícil situación producto de la cual pudieron haber sido declaradas Territorios No Autónomos, lo que hubiera conllevado entrar en una dinámica descolonizadora a todas luces prematura, si atendemos a la inexistencia en aquel momento de movimiento sociopolítico alguno que reivindicase tal idea. Fue la geografía, junto con una mala diplomacia, la responsable de situar a las Islas ante su verdadera dimensión geopolítica, como había ocurrido tantas veces en la historia insular y seguiría pasando en el futuro.

\section{Bibliografía}

Agbobli, A. (1992) Un destin tragique. NEA, Senegal: South livre.

Amin, S. (2004) "Geopolítica del imperialismo contemporáneo", en A. Borón (comp.) Nueva Hegemonía Mundial. Alternativas de cambio y movimientos sociales. Buenos Aires: CLACSO, 73-110.

Badián, S. (1967) Las vías del socialismo africano. Barcelona: ECP.

${ }^{21}$ MAE. Exp.029770. No84, 25/11/1960. 
Benot, Y. (1973) Ideologías de las independencias africanas. Barcelona: Dopesa.

Cabral, A. (1975) La descolonización del África portuguesa. Guinea Bissau. Buenos Aires: Ediciones Posifosia.

Calduch Cervera, R. (1994) La Política exterior española en el siglo XX. Madrid: Ediciones Ciencias Sociales.

Canales, C., y Del Rey, M. (2010) Breve historia de la guerra Ifni-Sáhara. Madrid: Nowtilus.

De la Torre Gómez, H., y Vicente, A. P. (1998) España-Portugal: estudios de historia contemporánea. Madrid: Editorial Complutense.

De la Torre, H., y Sánchez Cervelló, J. (1992) Portugal en el siglo XX. Madrid: Istmo.

Del Pino, D. (1983) La última guerra con Marruecos: Ceuta y Melilla. Barcelona: Argos Vergara.

Diego Aguirre, J.R. (1993) La última guerra colonial de España: Ifni-Sahara (1957-1958). Málaga: Algazara.

Espadas Burgos, M. (1988) Franquismo y política exterior. Madrid: Rialp.

Grimal, H. (1989) Historia de las descolonizaciones del siglo XX. Madrid: Iepala.

Haydara, A. (2012) L'influence des guerres de libération sur la révolution des oillets. París: L'Harmattan.

Heffer, J., y Launay, M. (1992) La Guerra Fría. Madrid: Akal.

Hobsbawm, E. (1995) Historia del siglo XX. Barcelona: Crítica.

Huband, M. (2004) África después de la Guerra Fría. Barcelona: Paidós.

Iglesias, M. (2010) Conflicto y cooperación entre España y Marruecos (1956-2008). Sevilla: Centro de Estudios Andaluces.

Iniesta, F. (2000) Kuma. Historia del África negra. Barcelona: Bellaterra.

Ki-Zerbo, J. (2011) Historia del África negra. De los orígenes a las independencias. Barcelona: Bellaterra.

Lacoste, Y. (2008) Geopolítica. Madrid: Síntesis.

Lacouture, J. (1972) Nasser. Barcelona: Dopesa.

Lleonart y Amsélem, A. J. (2002) España y ONU: 1952-1955. Madrid: CSIC.

López García, B., y Hernando de Larramendi, M. (eds.) (2010) España, el Mediterráneo y el mundo arabomusulmán. Barcelona: Icaria/Antrazit/IEMed.

Martínez Carrera, J. (1986) Historia de la descolonización, 1919-1986. Madrid: Istmo.

Meredith, M. (2011) África. Una historia de 50 años de independencia. Barcelona: Intermon Oxfam.

Ndaywel è Nziem, I. (2001) Historia del Congo. Madrid: Catarata.

Pereira Castañares, J.C. (2001) Historia de las relaciones internacionales contemporáneas. Barcelona: Ariel.

Piniés y Rubio, J. (2001) La descolonización española en las Naciones Unidas. Madrid: Centro de Estudios Políticos y Constitucionales. 
Prashad, V. (2012) Las naciones oscuras. Una historia del Tercer Mundo. Barcelona: Península.

Schatzberg, M. (1991) Mobutu or chaos: The United States and Zaire, 1960-1990. Washington, D.C.: University Press of America.

Taubman, W. (2005) Kruschev. El hombre y su época. Madrid: Ed. La Esfera.

Tusell, J., y Avilés Farré, J. (2000) La política exterior de España en el siglo XX. Madrid: UNED.

Witte, L. D. (2000) El asesinato de Lumumba. Barcelona: Crítica. 